\title{
Myocardial infarction caused by cardiac disease in disseminated zygomycosis
}

\author{
E W BENBOW, R F T MCMAHON \\ From the Department of Pathology, University of Manchester, Manchester
}

SUMMARY A case of disseminated zygomycosis is described, in which myocardial infarction rather than coincident coronary or heart disease was seen at necropsy. As zygomycosis is an opportunistic fungal infection, which tends to invade blood vessels, thereby causing thrombosis and infarction, it is surprising that cardiac disease is unusual and that premortem evidence of such disease has only rarely been reported.

Zygomycosis is an opportunistic fungal infection that has various clinical forms, including a disseminated type that affects multiple organs and which is particularly associated with leukaemia and cytotoxic chemotherapy. ${ }^{12}$ It has a clear affinity for blood vessels, often causing thrombosis and infarction. ${ }^{34}$ It is surprising, therefore, that cardiac disease seems to be an unusual component of disseminated zygomycosis ${ }^{5}$ and that subsequent myocardial infarction is a rare complication. $^{6}$

We describe a case of disseminated zygomycosis arising postoperatively in a man with severe generalised arteriosclerosis. Electrocardiographic evidence of acute myocardial infarction was confirmed by the necropsy findings.

\section{Case report}

\section{CLINICAL FINDINGS}

A 67 year old man who had had an aortoiliac bypass graft in 1979 was readmitted to a vascular surgery unit in November 1985. An aortic endarterectomy was performed in an attempt to relieve recurrent and increasingly severe symptoms of peripheral vascular disease.

After the operation he developed bronchopneumonia in the left lower lobe and was subjected to aggressive treatment with antibiotics and physiotherapy. Signs of an acute abdomen were noted nine days after the endarterectomy, and at laparotomy he was found to have a perforation of his small intestine at the duodenojejunal junction. There was extensive peritonitis with a right subphrenic abscess, and repair of the perforation and peritoneal toilet were carried out. He became hypotensive soon after the operation and required fluid replacement and inotropic agents to maintain cardiac output. His renal function deteri- orated temporarily and he needed ventilatory support for a short time. His general condition then improved, though copious flow of pus from the abdominal drains continued for seveial days. At this stage, his electrocardiogram (ECG) was unremarkable apart from a PR interval which was at the upper limit of normal (fig la). Seven days after the laparotomy his condition deteriorated, and he was found to have a cardiac arrhythmia. This settled, but four days after that he became hypotensive, and a further ECG showed atrial fibrillation with an uncontrolled ventricular rate; the $\mathbf{R}$ waves were lost, and an elevation of ST segment was present in leads $V_{2}$ to $V_{4}$ (fig $l b$ ). In the absence of $\mathrm{Q}$ waves these findings indicate an anterior myocardial infarct of no more than three days' duration, with only partial thickness involvement. He deteriorated rapidly and died the following day.

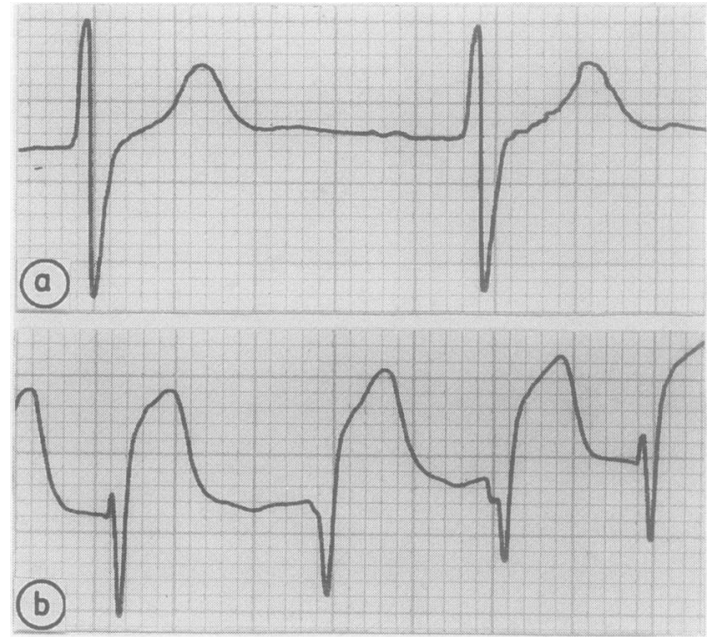

Fig 1 Electrocardiograms taken (a) seven days and (b) one day before death. Both are from lead $V_{3}$. 


\section{NECROPSY FINDINGS}

There was a recently sutured transverse abdominal incision which measured $30 \mathrm{~cm}$ in length, together with three drains in the lower abdomen. Each drain site exuded yellow-green fluid. There was a good deal of similar fluid found in the peritoneal cavity, and the viscera were covered with a copious fibrinopurulent exudate. There was an abscess cavity in the lesser sac, adjacent to a perforated ulcer on the greater curve of the stomach. Histological examination showed that the debris from the abscess cavity contained many fungal hyphae.

The heart weighed $550 \mathrm{~g}$; there was biventricular dilation and a moderate degree of left ventricular hypertrophy. The anteroseptal part of the wall of the left ventricle contained a mottled yellow-brown area, which measured about $3.5 \mathrm{~cm}$ in its long axis. The wall of the remainder of the left ventricle and of the other chambers contained scattered yellow foci of necrosis ranging from 0.2 to $0.5 \mathrm{~cm}$ in diameter. The epicardial parts of the coronary arteries showed moderate calcific atheroma, but no evidence of occlusion. Histologically, these discoloured areas showed the typical features of well established infarction, with separation of the anuclear fibres by a polymorph exudate (fig 2). In such areas fungal hyphae were seen within thrombus in the intramyocardial branches of the coronary arteries and in the cardiac veins; they invaded through the walls of the vessels and into the adjacent myocardium (fig 3 ). In other areas the

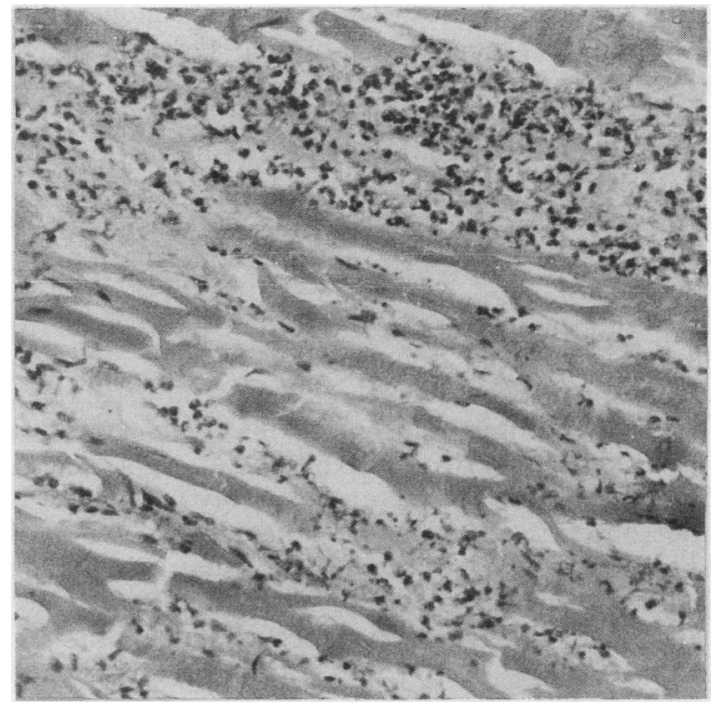

Fig 2 Left ventricular myocardium showing well established infarction, with necrosis and autolysis of muscle fibres and prominent infiltrate of neutrophil polymorphs.

(Haematoxylin and eosin stain.) Original magnification $\times 100$.



Fig 3 Intramyocardial artery and adjacent myocardium, both infiltrated by abundant fungal hyphae. There is thrombosis of vessel and infarction of myocardium. (Grocott's stain.) Original magnification $\times 18$ 
myocardium showed more recent infarction, without evidence of fungal invasion.

The lungs were oedematous, with foci of fungal bronchopneumonia which were more pronounced in the right lower lobe. Fungal hyphae were also seen in multiple renal and brain abscesses.

The thoracic and upper abdominal segments of the aorta showed severe atheroma with calcification, and a synthetic graft replaced the bifurcation and the lower part of the aorta. The abdominal branches of the aorta were all patent, and the graft anastomotic sites were intact.

The appearance of the fungus was similar at all the sites in which it was found. The hyphae were of variable diameter, but in general, were rather broad. There were some folds and kinks, and branches occurred irregularly but typically at right angles. Septa were seen, but these were scanty in most areas and showed no particular relation to the points of branching (fig 4). Two rounded structures, resembling sporangia, were seen protruding from the endocardium in a single section of the wall of the left atrium. Each was borne on the end of a thick hypha and had a well defined limiting membrane; there were no sterigmata on the surface, and no columella could be identified (fig 5). A few similar structures were found in a single tiny colony of fungus in the lung.

\section{Discussion}

Zygomycosis is often diagnosed on histology only;

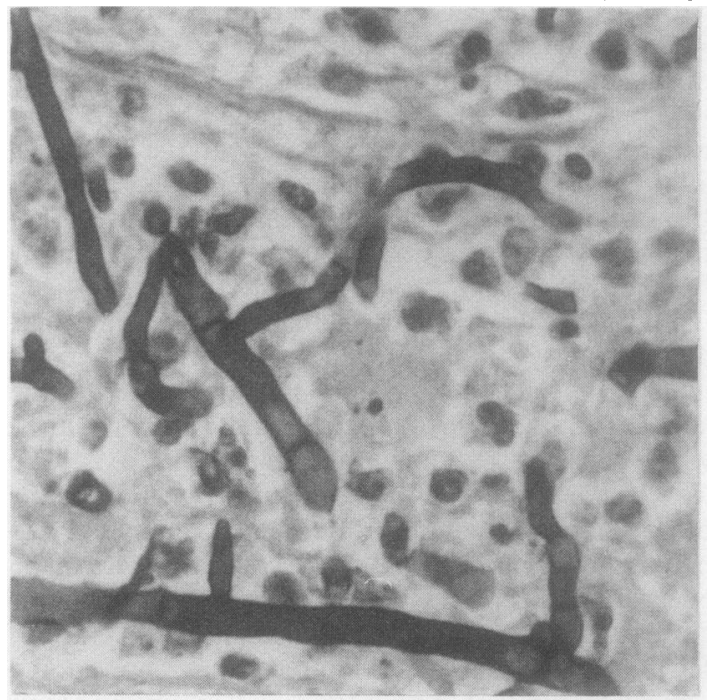

Fig 4 Fungal hyphae within lumen of intramyocardial vein. Hyphae are generally broad but of varying diameter.

Branching is at right angles, and both septa and pseudosepta are seen. (Grocott's stain.) Original magnification $\times 120$.

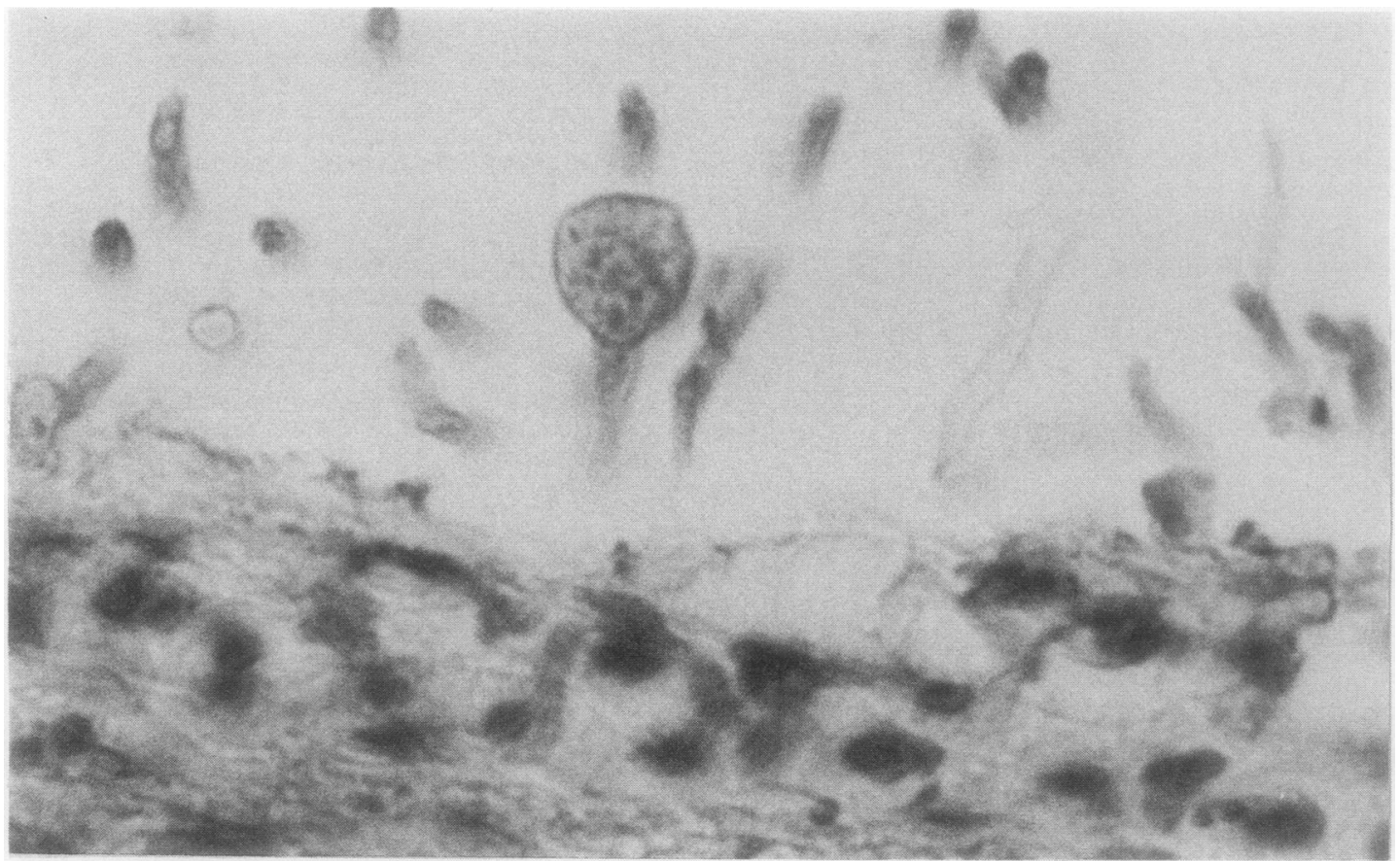

Fig 5 Left atrial endocardium with probable sporangium protruding into lumen. (Periodic acid Schiff stain.) Original magnification $\times 375$. 
cultures may not be taken because the presence of an infection is not anticipated, and even if they are taken the fungus may fail to grow. ${ }^{7}$ In tissue sections zygomycosis needs to be distinguished, in particular, from aspergillosis. This task may be difficult for the morphology is more variable in tissue than it is in culture, and both aspergillosis and zygomycosis may, on occasion, produce appearances which may simulate the other. ${ }^{48}$ First appearances may therefore be misleading, and histological diagnosis in most cases requires careful examination of those features that permit a distinction to be made.

In zygomycosis the hyphae branch irregularly and typically at right angles, whereas hyphal branching in aspergillosis is regular, mainly dichotomous, and usually at about $45^{\circ}$. Hyphal diameter in zygomycosis is variable and often relatively broad, in contrast to the narrower and more regular hyphae of aspergilli; those in zygomycosis are usually kinked to a variable degree, and the opposite walls of any one hypha are often not parallel with each other. Septa are common in aspergillosis and often occur at typical sites adjacent to the branches. In contrast, septa may be scanty in zygomycosis, and, indeed, some authors claim that a total lack of septation is typical. It is certainly true that aseptate hyphae are consistent with zygomycosis, but the corollary of this statement is not true for it is also known that some, if not all, species produce septa in culture, especially late ones, ${ }^{9}$ and in tissue. ${ }^{410}$ Pseudosepta, produced by minor kinks in the zygomycete hyphae, are often difficult to distinguish from true septa and lead to a false increase in the estimated prevalence of septa. The fungi in both conditions may be atypical when they are growing in a confined space, and it is important to assess those areas in histological sections where growth is relatively unimpeded, such as within thrombus or within a well established infarct. In our case we were able to assess those features of the fungus, both within thrombus, and myocardium, which showed well established infarction. The findings correspond well to the classical appearances of zygomycosis, apart from the presence of septa; there were, however, no areas where true septa were present with the incidence typical of aspergillosis.

The rounded structures within the left atrial lumen and within the lung closely resemble the sporangia of Zygomycetes, ${ }^{11}$ though they cannot be definitely distinguished from the chlamydoconidia that are occasionally produced. ${ }^{12}$ They clearly lack the ranks of sterigmata that are so characteristic of aspergilli.

Few positive cultures have been reported in previously published cases of cardiac zygomycosis, and several of those have been described as "Mucor," without any specific species identification. ${ }^{13-16}$ In two cases, however, the organism was identified as
Cunninghamella bertholletiae. ${ }^{1718}$ Further, one of the early cases of cardiac zygomycosis was also due to Cunninghamella $\mathrm{sp}$, though the actual species was not identified. ${ }^{13}$ This genus is a rare cause of human infection, and only eight reported cases have been due to Cunninghamella bertholletiae. ${ }^{18}$ Although this association with the heart may be mere coincidence, it might also represent a specific organ preference. Other similar species are known to prefer certain organs: Absidia corymbifera is associated with lung infection. ${ }^{19}$

Cardiac zygomycosis is usually seen as a component of disseminated zygomycosis. ${ }^{5}$ The heart is rarely the only organ affected in zygomycosis. ${ }^{2021}$ Virmani et al reviewed 115 cases of systemic zygomycosis from the files of the Armed Forces Institute of Pathology (AFIP) in Washington DC, and found only five with cardiac disease. ${ }^{5}$ All had widespread disease of other organs, particularly of the lungs. They also reviewed the published reports, apparently in a selective manner, and found four examples of disseminated zygomycosis with cardiac disease in an older report from the AFIP, ${ }^{3}$ together with six cases in reports from other centres. ${ }^{21-23}$ Their selectivity enhances the apparent rarity of cardiac zygomycosis, for at least 15 other cases were available in the literature at that time. ${ }^{13-1524-29}$ Several more have been added more recently. ${ }^{616-1830}$

Heart disease in zygomycosis may be endocardial, myocardial, or both. In addition, lesions in the lung may give rise to pericardial disease as a result of direct spread. Endocardial zygomycosis often overlies an area of myocardial infection and infarction and may thus be a consequence of invasion of a mural thrombus by hyphae from the wall of the heart. ${ }^{22}$ Alternatively, endocardial zygomycosis may precede and lead to myocardial zygomycosis. When the intramural component comes first, it is a consequence of embolism of hyphae to the coronary arteries. When such embolism causes infection and growth within an epicardial artery, there may be extensive myocardial infarction without invasion of the infarcted area by the fungus. ${ }^{15}$ This, however, seems to be the exception rather than the rule, for it is more usual to see thrombosis induced by fungus within small intramural arteries and for prominent growth of hyphae to occur within the infarcted myocardium. ${ }^{2122}$ In our case there were extensive areas where the presence of a well defined polymorph reaction suggested an infarct of some days' duration. The polymorphs were disposed in between the dead fibres in a pattern typical of myocardial infarction rather than that of an abscess, though the coincidence of such areas with hyphal invasion makes interpretation difficult. Other areas showed typical very recent infarction, with increased myocardial fibre eosinophilia and loss of 
nuclei and cross striations, but without a polymorph infiltrate or fungal invasion. This seems to be consistent with progressive infarction caused by thrombosis induced by fungus, followed by invasion of the infarcted stroma in each area by the fungus.

All of the reported cases of coronary and myocardial zygomycosis that we found were diagnosed as such only at necropsy. Most, like ours, were clinically unsuspected. Many of the previous reports provide a considerable amount of clinical detail, and so it is interesting to realise that no symptoms or signs of cardiac or major vessel disease could be found on review of the clinical notes in most of these


findings were non-specific, ${ }^{5}$ or dominated by endocardial events. ${ }^{22}$ ECG findings have rarely been reported, presumably because they have been negligible or unhelpful. In two cases where they were detailed the ECG findings were entirely non-specific, ${ }^{5}$ and in another two they were limited to changing heart blocks and arrhythmias. ${ }^{36}$ In only one previous report was there clear ECG evidence of myocardial infarction: Kolbeck et al describe a new right bundle branch block, associated with $\mathrm{Q}$ waves in several leads. ${ }^{18}$

Zygomycosis is an opportunistic infection, which is clearly being recognised more often than previously. ${ }^{23}$ One of the earlier reports of zygomycosis in the British literature came from a health district adjacent to ours, ${ }^{31}$ though the first case identified in this department was seen in $1984 .{ }^{32}$ Others have been seen since then, and zygomycosis now seems to be a well established opportunistic infection. Myocardial disease is an unusual complication of the disseminated form of zygomycosis but should be included within the differential diagnosis when evidence of myocardial ischaemia or infarction occurs in a patient at risk of such opportunistic infection.

We are grateful to Dr HG Love for reviewing the electrocardiograms and to Dr RW Stoddart for his invaluable comments. We thank the university department of medical illustration and Mrs Jane Crosby for help with the photographs.

\section{References}

1 Lehrer RI, Howard DH, Sypherd PS, Edwards JE, Segal GP, Winston DJ. Mucormycosis. Ann Intern Med 1980;93:93-108.

2 Benbow EW, Stoddart RW. Systemic zygomycosis. Postgrad Med $J$ 1986;62;985-960

3 Straatsma BR, Zimmerman LE, Gass JDM. Phycomycosis. A clinicopathologic study of 51 cases. Lab Invest 1962;11:963-85.

4 Rippon JW. Medical mycology. The pathogenic fungi and the pathogenic actinomycetes. Philadelphia: WB Saunders Co. 1982:615-40.

5 Virmani R, Connor DH, McAllister HA. Cardiac mucormycosis. A report of five patients and review of 14 previously reported cases. Am J Clin Pathol 1982;78:42-7.

6 Tuder RM. Myocardial infarct in disseminated mucormycosis: case report with special emphasis on the pathogenic mechanisms. Mycopathologia 1985;89:81-8.

7 Stoddart RW, Herbertson BM. The use of fluorescein-labelled lectins in the detection and identification of fungi pathogenic for man: a preliminary study. J Med Microbiol 1978;11:315-24.

8 Rippon JW. Medical mycology. The pathogenic fungi and the pathogenic actinomycetes. Philadelphia: WB Saunders Co. 1982:565-94.

9 Webster J. Introduction to fungi. 2nd Ed. Cambridge: Cambridge University Press, 1980:193.

10 Chandler FW, Kaplan W. Ajello L. A colour atlas and texthook of the histopathology of mycotic diseases. London: Wolfe Medical Publications, 1980:294-9.

11 Emmons CW. Binford CH, Utz JP, Kwon-Chung KJ. Medical mycology. 3rd ed. Philadelphia: Lea and Febiger, 1977:22-3.

12 Chandler FW, Watts JC, Kaplan W, Hendry AT, McGinnis MR. Ajello L. Zygomycosis. Report of four cases with formation of chlamydoconidia in tissue. Am J Clin Pathol 1985;84:99-103.

13 Hutter RVP. Phycomycetous infection (mucormycosis) in cancer patients: a complication of therapy. Cancer 1959;12:330-50.

14 Symmers WStC. Histopathology of opportunistic fungal infections. In: Chick EW, Balows A, Furdow ML, eds. Opportunistic fungal infections. Proceedings of the 2nd international conference. Springfield, Illinois: Charles C Thomas. 1975. 269-84.

15 Connor BA, Anderson RJ, Smith JW. Mucor mediastinitis. Chest 1979;75:524-6.

16 Bhaduri S, Kurrle E, Vanek E. Spanel R. Mucormycosis in the immunocompromised host. Infection 1983;11:170-2.

17 McGinnis MR, Walter DH, Dominy IE, Kaplan W. Zygomycosis caused by Cunninghamella bertholletiae. Clinical and pathologic aspects. Arch Pathol Lah Med 1982;106:282-6.

18 Kolbeck PC, Makhoul RG, Bollinger RR, Sanfilippo F. Widely disseminated Cunninghamella mucormycosis in an adult renal transplant patient: case report and review of the literature. $\mathrm{Am}$ J Clin Pathol 1985;83:747-53.

19 Scholer HJ, Müller E, Schipper MAA. Mucorales. In: Howard $\mathrm{DH}$, ed. Fungi pathogenic for humans and animals. Part $A$. Biology. New York: Marcel Dekker, 1983:9-59.

20 Khicha GJ, Berroya RB, Escano FB, Lee CS. Mucormycosis in a mitral prosthesis. J Thorac Cardiovasc Surg 1972;63:903-5.

21 Torack RM. Fungus infections associated with antibiotic and steroid therapy. Am J Med 1957;22:872-82.

22 Rabin ER, Lundberg GD. Mitchell ET. Mucormycosis in severely burned patients. Report of two cases with extensive destruction of the face and nasal cavity. $N$ Engl $J$ Med 1961;264:1286-9.

23 Meyer RD, Rosen P. Armstrong D. Phycomycosis complicating leukaemia and lymphoma. Ann Intern Med 1972:77:871-9.

24 Zimmerman LE. Fatal fungus infections complicating other diseases. Am J Clin Pathol 1955;25:46-65.

25 Parkhurst GF. Vlahides GD. Fatal opportunistic fungus disease. JAMA 1967;202:279-81

26 Vorreith M. Viscerálni mukormykózy. Cesk Patol 1969;5:161-7.

27 Satir AA, Dafa'ala M, Mahgoub S. Musa AR. Systemic phycomycosis. Br Med J 1971:i:440.

28 Erdos MS, Butt K, Weinstein L. Mucormycotic endocarditis of the pulmonary valve. $J A M A$ 1972;222:951-3.

29 Agger WA, Maki DG. Mucormycosis. A complication of critical care. Arch Intern Med 1978;138:925-7.

30 Parfrey NA. Improved diagnosis and prognosis of mucormycosis. A clinicopathologic study of 33 cases. Medicine (Baltimore) 1986;65:113-23.

31 Winston RM. Phycomycosis of the bronchus. J Clin Pathol 1965; 18:729-31.

32 Benbow EW, Delamore IW, Stoddart RW, Reid H. Disseminated zygomycosis associated with erythroleukaemia: confirmation by lectin stains. J Clin Pathol 1985;38:1039-44.

Requests for reprints to: Dr EW Benbow, Department of Pathology, Stopford Building, University of Manchester, Oxford Road, Manchester, M13 9PT, England 